\title{
CALOGÊNESE EM DIFERENTES ESTACAS DE CAQUIZEIRO TRATADAS COM FRIO E ÁCIDO INDOLBUTÍRICO
}

\section{CALOGENESIS IN DIFFERENT CUTTINGS OF JAPANESE PERSIMMON TREATED WITH CHILL AND INDOLBUTIRIC ACID}

\author{
Ivo Ditos da SILVA 1 \\ Rudival FAQUIM ${ }^{1}$ \\ Ruy Inacio Neiva de CARVALHO²
}

\begin{abstract}
RESUMO
Objetivou-se avaliar a influência da época de coleta, tratamento com frio e doses de ácido indolbutírico (AIB) na calogênese em estacas de caquizeiro 'Fuyu'. Formulou-se a hipótese que sendo o caquizeiro uma espécie que apresenta dormência em intensidades variadas durante o outono e inverno, então o crescimento celular necessário à calogênese é influenciado pela época do ano e pelo efeito do frio, que juntos podem tornar as células responsivas à ação das auxinas. Os ramos foram coletados em 29/08 (estacas lenhosas) e 21/02 (estacas semi-lenhosas) e em cada época, metade dos ramos foi tratada com 504 horas de frio $\left(4 \mathrm{a} 7^{\circ} \mathrm{C}\right)$ e metade foi submetida à estaquia após tratamento com AIB $\left(0,1.000,2.000\right.$ e $\left.3.000 \mathrm{mg} \mathrm{L}^{-1}\right)$. Determinou-se a velocidade de brotação das gemas e após 60 dias foram avaliadas a porcentagem de estacas com calo, brotadas, dormentes e mortas. A calogênese foi maior $(20,83 \%)$ nas estacas semi-lenhosas não tratadas com frio. Nas estacas lenhosas não houve formação de calos. Nas estacas semi-lenhosas a velocidade de brotação foi menor que nas estacas lenhosas mas nestas últimas houve maior mortalidade $(90,04 \%)$. O tratamento com AIB não influenciou a calogênese. Concluiu-se que a calogênese foi favorecida nas estacas semi-lenhosas não tratadas com frio. A velocidade de brotação foi mais intensa nas estacas lenhosas e tratadas com frio. As estacas semi-lenhosas apresentaram-se mais dormentes, principalmente as submetidas ao tratamento com frio. Houve um maior percentual de estacas mortas entre as estacas lenhosas tratadas com frio.
\end{abstract}

Palavras-chave: Diospyros kaki L., estaquia, auxinas, brotação.

\begin{abstract}
The objective of this work was to evaluate the influence of collection date, chill treatment and doses of indolbutiric acid (IBA) in the calogenesis in cuttings of 'Fuyu' japanese persimmon. The japanese persimmon tree presents different intensity of bud dormancy during the autumn and winter, then the cellular growth needed to the calogenesis is influenced by the season and the chill occurence, and both can determine the cell hability to respond the auxins action. The branches were collected in August, $8^{\text {th }}$ (hardwood cuttings) and February, $2^{\text {nd }}$ (semi-hardwood cuttings) and, in each date, $50 \%$ of branches were treated with 504 hours of chill $\left(4\right.$ to $\left.7^{\circ} \mathrm{C}\right)$ and the remaining branches were used to prepare the witch were then submitted to differents dosis of IBA $\left(0,1,000,2,000\right.$ and $\left.3,000 \mathrm{mg} \mathrm{L}^{-1}\right)$. The velocity of budburst was determined and after 60 days the percentage of cuttings with callus, sprouted, dorment and dead were evaluated. The calogenesis occured in $20.83 \%$ of the semi-hardwood cuttings without the chill treatment. There was not calogenesis in the hardwood cuttings. In the semi-hardwood cuttings, the velocity of budburst was smaller than the hardwood cuttings, however the last one presented $90.04 \%$ of mortality. The IBA treatment do not influenced the calogenesis. The calogenesis was stimulated in the semi-hardwood cuttings without chill treatment. The budburst velocity was more intense in the hardwood cuttings treated with chill. The chill treatment induced the dormancy of buds in the semi-hardwood cuttings. The mortality was bigger in the hardwood cuttings treated with chill.
\end{abstract}

Key-words: Diospyros kaki L., cutting, auxins, budburst.

\footnotetext{
${ }^{1}$ Estudante de Agronomia, PUCPR, CCAA. ivo.ds@uol.com.br e rudi2002@ig.com.br

${ }^{2}$ Eng. Agrônomo, Dr., Professor Titular do Centro de Ciências Agrárias e Ambientais da Pontifícia Universidade Católica do Paraná, Campus São José dos Pinhais. Rodovia BR 376, km 14, CEP 83010-500, São José dos Pinhais, Paraná. Fone: (41) 3299-4300. ruy.carvalho@pucpr.br
} 


\section{INTRODUÇÃO}

O caquizeiro (Diospyros kaki L.) é a espécie de maior interesse comercial na fruticultura entre as aproximadamente 200 espécies do gênero Diospyros que produzem frutos comestíveis (Gomes, 1994). A muda de caquizeiro é obtida por garfagem em portaenxertos formados a partir de sementes, gerando pomares heterogêneos, fato que não ocorreria se os porta-enxertos fossem obtidos por estacas, como já realizado para outras frutíferas.

Em ameixeira, a estaquia é uma alternativa viável para obtenção de mudas mas a sua eficiência varia em função da cultivar e do tratamento com AIB (MINDÊLLO NETO et al., 2006) e da época de coleta das estacas (ROSSAl et al., 1997). Em pessegueiro, a eficiência da estaquia varia de acordo com a concentração de AIB utilizada, com melhores resultados obtidos nas concentrações de 2.000 a 3.000 $\mathrm{mg} \mathrm{L}^{-1}$ (AGUIAR et al., 2005; MINDÊLLO NETO, 2005; TOFANELLI et al., 2002a; TOFANELLI et al., 2002b) e pela imersão rápida por cinco segundos na solução de AIB (TOFANELLI et al., 2003a; TOFANELLI et al., $2003 \mathrm{~b}$ ). Outros fatores também influenciam a rizogênese em estacas de pessegueiro como a época de coleta (DUTRA et al., 2002) e tipo de corte basal na estaca (TOFANELLI et al., 2005). A estaquia para produção de mudas também já foi estudada para outras espécies como a aceroleira (GONTIJO et al., 2003) e o quivizeiro (PAES et al., 2003).

A viabilidade de propagação do caquizeiro por estacas tem sido estudada, principalmente com relação ao uso de auxinas, como o ácido indolbutírico (AIB), e à época de coleta das estacas de diferentes cultivares. Estacas herbáceas de caquizeiro 'Fuyu' apresentaram maior tendência na propagação via estaquia porém apresentando apenas $4,05 \%$ de enraizamento. Em estacas lenhosas, não houve enraizamento e a sobrevivência aos 90 dias foi de apenas 43,29 \% (BASTOS et al., 2005). Biasi et al. (2002) em experimento com AIB nas concentrações de 0 a $4.000 \mathrm{mg} \mathrm{L}^{-1}$, não obtiveram enraizamento, brotação ou calo na base das estacas semi-lenhosas do caquizeiro 'Fuyu'. Por outro lado, os tecidos radiculares do caquizeiro possuíram maior competência morfogenética do que os caulinares, respondendo de forma mais intensa aos estímulos para formação adventícia de novos órgãos.

A morfogênese em tecidos de caquizeiro em laboratório é mais viável pois na estaquia in vitro foi obtida uma taxa de $66 \%$ de enraizamento com média de 4,7 raízes por estaca (BIASI et al., 2002). O estabelecimento in vitro do caquizeiro 'Fuyu' também pode ser obtido pelo cultivo de ápices meristemáticos (CARVALHO et al., 2004a), segmentos radiculares (CARVALHO e BIASI, 2004) ou embriões zigóticos (CARVALHO et al., 2004b).

Dentro da morfogênese, a calogênese é um prenúncio importante para a formação de raízes adventícias em estacas. O processo de rizogênese é dividido em quatro fases que abrangem desde as alterações fisiológicas nas células das estacas até a visualização da nova raiz formada. Na primeira fase de indução, ocorre o acúmulo de auxinas em locais específicos da estaca. A segunda fase corresponde aos primeiros estágios da iniciação, ocorrendo estímulo à divisão celular, e a terceira fase são os estágios finais da iniciação, acontecendo a organização dos primórdios radiculares. Na quarta fase as células iniciais se diferenciam e o primórdio radicial se desenvolve e emerge através do córtex e epiderme acompanhados da conexão com o sistema vascular da estaca, formando um novo sistema de raízes adventícias (FACHINELLO et al.,1995).

Como o caquizeiro necessita de frio para superação da dormência, algumas gemas das estacas podem ficar dormentes na estaquia, o que pode estar relacionado à quantia insuficiente de horas de frio recebido a campo. Em condições de pouco frio, a quebra de dormência pela aplicação de cianamida hidrogenada estimulou a brotação das gemas de caquizeiro (MIZOBUTSI et al., 2003). Carvalho e Zanette (2004) verificaram redução do tempo médio para brotação de gemas de macieira em estacas submetidas ao teste biológico de dormência após a aplicação de 1.440 horas de frio $\left(4 \mathrm{a} 7^{\circ} \mathrm{C}\right)$. Herter et al. (2001) concluíram que o estado inercial das gemas terminais de estacas de pereira cultivar 'Carrick' diminuiu com o aumento do número de horas de frio a que foram submetidas, havendo a superação da dormência com a aplicação de no mínimo 800 horas de frio.

Segundo Zanette (1982) temperaturas baixas $\left(3^{\circ} \mathrm{C}\right)$ quebram a dormência das gemas e estimulam a rizogênese em porta-enxertos de macieira. Assim, a calogênese, fase inicial da rizogênese, pode ser influenciada pela habilidade fisiológica das células da estaca em se diferenciar em novos tecidos e a dormência é um evento fisiológico que restringe esta capacidade de crescimento celular.

Assim, formulou-se a hipótese que sendo o caquizeiro uma espécie que apresenta dormência em intensidades variadas durante o outono e inverno, então o crescimento celular necessário à calogênese é influenciado pela época do ano e pelo efeito do frio que juntos podem tornar as células responsivas à ação das auxinas.

O objetivo deste trabalho foi verificar a influência da época de coleta e do tratamento com frio e ácido indolbutírico na calogênese em estacas de caquizeiro 'Fuyu'.

\section{METODOLOGIA}

Os ramos de caquizeiro 'Fuyu' com $30 \mathrm{~cm}$ de comprimento, com disposição espacial oblíqua e portadores de gema terminal íntegra foram coletados nos dias 29 de agosto de 2005 (estacas lenhosas) e 21 de fevereiro de 2006 (estacas semi-lenhosas) em pomar com onze anos de idade com espaçamento de $6 \times 4 \mathrm{~m}$ na Fazenda Experimental Gralha Azul em Fazenda Rio Grande - PR (Latitude de 2539' S; Longitude de $49^{\circ} 16^{\prime} \mathrm{O}$ e altitude média de $895 \mathrm{~m}$ ).

Metade dos ramos coletados em cada data 
foram mantidos na posição vertical com suas bases acondicionadas em vaso com vermiculita umedecida com água e mantidas em geladeira a temperatura de 4 a $7^{\circ} \mathrm{C}$ durante 504 horas. A outra metade foi imediatamente levada à casa de vegetação com irrigação e ventilação automáticas do Campus São José dos Pinhais da Pontifícia Universidade Católica do Paraná para procedimento da estaquia. As folhas das estacas semi-lenhosas foram retiradas imediatamente após a coleta. As estacas foram preparadas com $25 \mathrm{~cm}$ de comprimento por meio de um corte em bisel na sua base ao lado oposto de uma gema e mantendo-se no ápice a gema terminal. Foram utilizadas embalagens plásticas pretas com 15 $\mathrm{cm}$ de altura e diâmetro de $6 \mathrm{~cm}$ (volume de $424 \mathrm{~cm}^{3}$ ) preenchidas com substrato formado pela mistura de solo e vermiculita na proporção de 2:1 (v/v).

Efetuou-se também o tratamento com ácido indolbutírico (AIB) em quatro diferentes concentrações $\left(0,1.000,2.000\right.$ e $\left.3.000 \mathrm{mg} \mathrm{L}^{-1}\right)$ diluídas em solução de água e álcool na proporção 1:1 (v/v). O tratamento foi feito pela imersão de $3 \mathrm{~cm}$ da base das estacas por cinco segundos imediatamente após o corte da região basal e em seguida as estacas tiveram metade de seu comprimento enterrada no substrato.

Após a instalação determinou-se o número de dias para início de brotação das gemas e após 60 dias foram avaliadas a porcentagem de estacas com calo, estacas somente brotadas, estacas dormentes (vivas mas sem raíz, sem calo e sem brotação), estacas mortas e a velocidade de brotação (gemas por dia) obtida pela fórmula citada por Carvalho e Zanette (2004):

$$
V B=\mathbf{O}\left(n_{i} / t_{i}\right)
$$
tempo "i"

Onde: $\mathrm{n}=$ número de gemas brotadas no a 60 dias)

$$
\mathrm{t} \text { = tempo após a instalação da estaquia (i } \mathbf{O}_{1}
$$

O frio regional ocorrido durante os meses de outono e inverno até a data de coleta dos ramos lenhosos, quantificado pelo número de horas de frio abaixo de $7,2^{\circ} \mathrm{C}$ com base em dados disponíveis pelo Simepar (2005) foi de 80 horas. Convertendo-se as temperaturas horárias em unidades de frio pelo modelo Utah proposto por Richardson et al. (1974), os valores acumulados de maio até coleta dos ramos em agosto foram de -522,5 UF o que caracterizou um ano de baixa ocorrência de frio no outono e inverno.

O delineamento experimental utilizado foi o completamente casualizado em um esquema fatorial $2 \times 2 \times 4$ representados pelas duas épocas de coleta, tratamento ou não com frio e as diferentes doses de AIB. Utilizaram-se 3 repetições por tratamento com 10 estacas por parcela, totalizando 240 estacas em cada época de coleta. As médias com diferença significativa pelo teste $\mathrm{F}$ da análise de variância foram submetidas ao teste de Tukey ao nível de significância de $5 \%$ para os fatores época de coleta e tratamento com frio, e à análise de regressão para o fator dose de AIB.

RESULTADOS E DISCUSSÃO

A calogênese ocorreu em maior porcentagem na região do corte basal nas estacas semi-lenhosas $(20,83 \%)$ que não receberam tratamento com 504 horas de frio (Tabela 1), não havendo formação de raízes. Nas estacas semi-lenhosas tratadas com frio houve redução da formação de calos para apenas 2,5 $\%$. Porém, a porcentagem de estacas dormentes aumentou de 13,33 para 45,83\% (Tabela 2) indicando que o tratamento com frio induziu a estaca à dormência, fazendo com que as células dormentes das estacas permanecessem inaptas à diferenciação necessária à formação do calo.

As estacas lenhosas não tiveram formação de raízes e calos e o AIB não influenciou a calogênese e a velocidade de brotação em nenhum tipo de estaca. Estes resultados são semelhantes aos obtidos por Bastos et al. (2005) com relação às estacas lenhosas que, trabalhando com diferentes cultivares de caquizeiro, não obtiveram formação de calo e emissão de raíz em nenhuma das cultivares estudadas, tratadas com diferentes concentrações de AIB (0; 3.000 e $6.000 \mathrm{mg} \mathrm{L}^{-1}$ por vinte segundos). Biasi et al. (2002) constataram que a utilização de AIB em concentrações de 0 a $4.000 \mathrm{mg} \mathrm{L}^{-1}$ não apresentou efeito sobre a emissão de raízes em estacas semilenhosas de caquizeiro 'Fuyu'.

A dificuldade de enraizamento de estacas e as diferentes respostas em função da época de coleta e aplicação do AIB também ocorrem para outras plantas frutíferas. Estacas de quivizeiro apresentaram baixo enraizamento na primavera, verão e outono variando de 0 a $35 \%$ mesmo com uso de auxinas e somente no inverno com uso de $5.000 \mathrm{mg} \mathrm{L}^{-1}$ de ANA houve 70 $\%$ de enraizamento (PAES et al., 2003). Em outras espécies o efeito do AIB foi mais favorável como o encontrado por Oliveira et al. (2003) que obtiveram aumento na porcentagem de enraizamento de estacas lenhosas e semi-lenhosas de várias cultivares de pessegueiro com o uso da concentração de $1.500 \mathrm{mg}$ $\mathrm{L}^{-1}$, considerada suficiente para proporcionar enraizamento entre $65,3 \%$ e $97,2 \%$. Porém, o uso de AIB nas concentrações de 2.000 a $3.000 \mathrm{mg} \mathrm{L}^{-1}$ também foi considerado favorável ao enraizamento de estacas de pessegueiro (AGUIAR et al., 2005; MINDÉLLO NETO, 2005; TOFANELLI et al., 2002a; TOFANELLI et al., 2002b).

Nas estacas lenhosas de caquizeiro, mesmo com tratamento com frio, não houve calogênese (Tabela 1) porém, o efeito do frio foi contrário ao das estacas semi-lenhosas, pois o frio aplicado no mês de agosto favoreceu a quebra de dormência e estimulou a velocidade de brotação que passou de 0,50 para 0,73 gema por dia (Tabela 3). 
SILVA, I.D. et al. Calogênese em diferentes estacas...

TABELA 1 - Formação de calo (\%) em estacas de caquizeiro 'Fuyu', em decorrência da época de coleta e tratamento ou não com 504 horas de frio antes da estaquia realizada em agosto e fevereiro em São José dos Pinhais, Paraná.

\begin{tabular}{|c|c|c|c|}
\hline \multirow{3}{*}{ Tipo de estaca } & \multicolumn{2}{|c|}{ Tratamento com frio* } & \multirow[b]{2}{*}{ Média } \\
\hline & Sem & Com & \\
\hline & \multicolumn{2}{|c|}{ Estacas com calo (\%) } & \\
\hline Lenhosa & $0,00 \mathrm{Ab}$ & $0,0 \quad \mathrm{Aa}$ & $0,00 \mathrm{~b}$ \\
\hline Semi-lenhosa & $20,83 \mathrm{Aa}$ & $2,5 \mathrm{Ba}$ & 11,66 a \\
\hline Média & $10,41 \quad A$ & $1,25 \mathrm{~B}$ & \\
\hline
\end{tabular}

$\mathrm{CV}=18,06 \%$

*Médias seguidas por letras distintas, minúsculas nas colunas e maiúsculas nas linhas, diferem entre si pelo teste de Tukey ao nível de significância de $5 \%$.

TABELA2 - Estacas dormentes (\%) de caquizeiro 'Fuyu' em decorrência da época de coleta e tratamento ou não com 504 horas de frio antes da estaquia realizada em agosto e fevereiro em São José dos Pinhais, Paraná.

\begin{tabular}{|c|c|c|c|}
\hline \multirow{3}{*}{ Tipo de estaca } & \multicolumn{2}{|c|}{ Tratamento com frio* } & \multirow[b]{2}{*}{ Média } \\
\hline & Sem & Com & \\
\hline & \multicolumn{2}{|c|}{ Estacas dormentes (\%) } & \\
\hline Lenhosa & $0,83 \mathrm{Ab}$ & $0,00 \mathrm{Ab}$ & $0,42 \mathrm{k}$ \\
\hline Semi-lenhosa & $13,33 \mathrm{Ba}$ & $45,83 \mathrm{Aa}$ & 28,33 \\
\hline Média & $7,08 \quad \mathrm{~B}$ & $22,91 \quad A$ & \\
\hline
\end{tabular}

*Médias seguidas por letras distintas, minúsculas nas colunas e maiúsculas nas linhas, diferem entre si pelo teste de Tukey ao nível de significância de $5 \%$.

A velocidade de brotação das estacas lenhosas foi maior que a obtida nas estacas semi-lenhosas. As estacas lenhosas tratadas com frio tiveram velocidade de brotação maior que as não tratadas (Tabela 3). Carvalho e Zanette (2004) detectaram que em teste biológico de dormência, as estacas de macieira 'Imperial Gala' tratadas com 1440 horas de frio suplementar também tiveram maior velocidade de brotação. Porém, verificou-se que no caquizeiro a quebra de dormência pela ação do frio e a brotação da gema são processos fisiológicos mais rápidos que a calogênese e, consequentemente, a rizogênese, fato que resultou em maior porcentagem de estacas mortas $(95,83 \%)$ (Tabela 4).

As estacas lenhosas e semi-lenhosas tratadas com frio permaneceram vivas e brotadas com menor percentual $(4,2 \%)$ após 60 dias da estaquia em relação às que não receberam o tratamento com frio
$(19,2 \%)$. O frio nas estacas semi-lenhosas exerceu efeito antecipado, levando um maior número de gemas à dormência e o frio nas estacas lenhosas quebrou a dormência e estimulou a brotação antecipada das gemas, levando a estaca à morte (Tabelas 2, 3 e 4). No campo, esta dormência pode ser quebrada usando cianamida hidrogenada como trabalho realizado por Mizobutsi et al. (2003) com estacas dormentes de caquizeiro 'Rubi', produzindo a antecipação da brotação quando comparado com as plantas não pulverizadas.

A porcentagem de estacas mortas foi maior entre as estacas lenhosas e tratadas com frio (Tabela 4). Tal fato se deve à maior velocidade de brotação constatada nas estacas lenhosas tratadas com 504 horas de frio, fazendo com que brotassem rapidamente mas morressem, devido a não formação de calos e raízes.

TABELA 3 - Velocidade de brotação (gemas por dia) em estacas de caquizeiro 'Fuyu' em decorrência da época de coleta e tratamento ou não com 504 horas de frio antes da estaquia realizada em agosto e fevereiro em São José dos Pinhais, Paraná.

\begin{tabular}{|c|c|c|c|}
\hline \multirow{3}{*}{ Tipo de estaca } & \multicolumn{2}{|c|}{ Tratamento com frio* } & \multirow[b]{2}{*}{ Média } \\
\hline & Sem & Com & \\
\hline & \multicolumn{2}{|c|}{ Velocidade de brotação (gemas por dia) } & \\
\hline Lenhosa & $0,50 \mathrm{Ba}$ & $0,73 \mathrm{Aa}$ & $0,62 \mathrm{a}$ \\
\hline Semi-lenhosa & $0,26 \mathrm{Ab}$ & $0,21 \mathrm{Ab}$ & $0,24 \mathrm{~b}$ \\
\hline Média & $0,38 \mathrm{~B}$ & $0,47 \mathrm{~A}$ & \\
\hline
\end{tabular}

*Médias seguidas por letras distintas, minúsculas nas colunas e maiúsculas nas linhas, diferem entre si pelo teste de Tukey ao nível de significância de $5 \%$. 
SILVA, I.D. et al. Calogênese em diferentes estacas...

TABELA 4 - Estacas mortas (\%) de caquizeiro 'Fuyu', em decorrência da época de coleta e tratamento ou não com 504 horas de frio antes da estaquia realizada em agosto e fevereiro em São José dos Pinhais, Paraná.

\begin{tabular}{|c|c|c|c|}
\hline \multirow[t]{3}{*}{ Tipo de estaca } & \multicolumn{2}{|c|}{ Tratamento com frio* } & \multirow[b]{2}{*}{ Média } \\
\hline & Sem & Com & \\
\hline & \multicolumn{2}{|c|}{ Estacas mortas (\%) } & \\
\hline Lenhosa & $85,00^{\text {ns }}$ & $95,83^{\text {nS }}$ & $90,04 \mathrm{a}$ \\
\hline Semi-lenhosa & 41,67 & 47,50 & $44,58 \mathrm{~b}$ \\
\hline Média & $63,33 \mathrm{~B}$ & $71,66 \mathrm{~A}$ & \\
\hline
\end{tabular}

CV $=9,06 \%$

* Médias seguidas por letras distintas, minúsculas nas colunas e maiúsculas nas linhas, diferem entre si pelo teste de Tukey ao nível de significância de $5 \%$.

ns = Diferença não significativa

O AIB teve efeito significativo somente com relação à mortalidade das estacas havendo menos estacas mortas na testemunha e nas maiores concentrações (Figura 1). Oliveira et al. (2003), trabalhando com estacas lenhosas de pessegueiro das cultivares Coral, Sinuelo, Marli e Eldorado, constataram maior mortalidade nas estacas tratadas com $1.500 \mathrm{mg} \mathrm{L}^{-1}$ de AIB.

Bastos et al. (2005) constataram que, para o ensaio envolvendo estacas lenhosas de caquizeiro das cultivares Pomelo, Rama Forte, Taubaté, Giombo e
Fuyu, apesar de não haver formação de raízes e calos nas estacas, houve diferença entre as cultivares e as concentrações de AIB para porcentagem de sobrevivência. Para as cultivares Fuyu e Rama Forte a maior sobrevivência aconteceu na ausência de tratamento com AIB. A maior sobrevivência nas maiores concentrações de AIB pode estar relacionada à baixa quantidade de auxina endógena nas estacas, uma vez que em algumas cultivares, a presença do AIB aumentou a taxa de sobrevivência como ocorrido na cultivar Giombo (3.000 mg L-1).

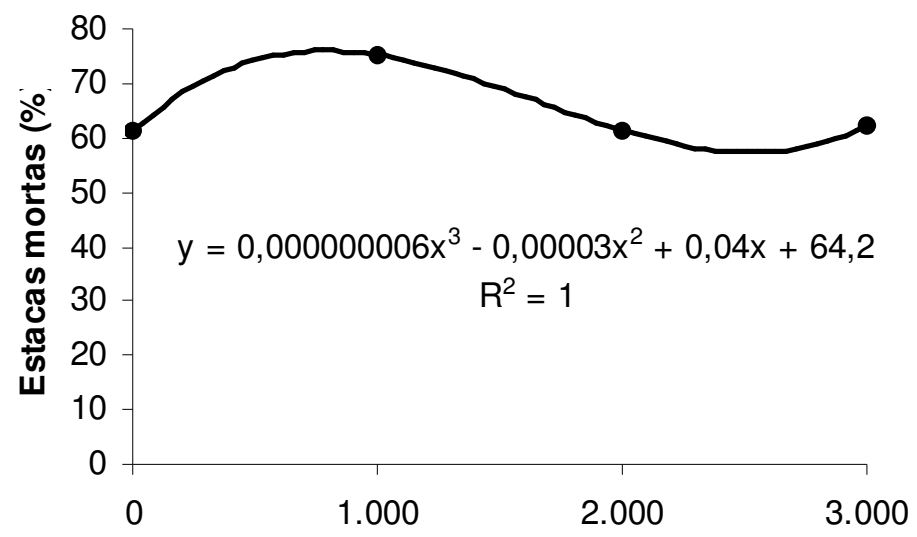

Doses de AIB ( $\left.\mathrm{mg} \mathrm{L}^{-1}\right)$

FIGURA 1 - Estacas mortas (\%) de caquizeiro 'Fuyu' em decorrência do tratamento com diferentes concentrações de AIB em estaquia realizada em agosto e fevereiro em São José dos Pinhais, Paraná.

\section{CONCLUSÕES}

Há dificuldade de propagação do caquizeiro por estaquia mas a calogênese é favorecida nas estacas semi-lenhosas coletadas em fevereiro e não tratadas com frio, mas não é influenciada pelo tratamento com o ácido indolbutírico.
A velocidade de brotação é mais intensa e o percentual das estacas mortas é maior nas estacas lenhosas e tratadas com frio.

As estacas semi-lenhosas coletadas em fevereiro apresentam-se mais dormentes, principalmente as submetidas ao tratamento com frio. 
SILVA, I.D. et al. Calogênese em diferentes estacas...

\section{REFERÊNCIAS}

1. AGUIAR, R. S.; SANTOS, C. E.; ZIETEMANN, C.; ASSIS, A. M.; MARAIS, V. J.; ROBERTO, S. R. Enraizamento de estacas semi-lenhosas do pessegueiro 'Okinawa' submetidas a diferentes dosagens de ácido indolbutírico. Acta Scientiarum, Maringá, v.27, n.3, p.461-466, 2005

2. BASTOS, D. C.; PIO, F.; SCARPARE FILHO, J. A.; LIBARDI, M. N.; ALMEIDA, L. F. P.; ENTELMANN, F. A. Enraizamento de estacas lenhosas e herbáceas de cultivares de caquizeiro com diferentes concentrações de ácido indolbutírico. Revista Brasileira de Fruticultura, Jaboticabal, v.27, n.1, p.182-184, 2005.

3. BIASI, L. A.; CARVALHO, D. C.; WOLF, G. D.; ZANETTE. F. Potencial organogenético de tecidos caulinares e radiculares de caquizeiro. Revista Brasileira de Fruticultura, Jaboticabal, v.24, n.1, p.29-34, 2002.

4. CARVALHO, D. C.; BIASI, L. A. Organogênese do caquizeiro a partir de segmentos radiculares. Ciência Rural, Santa Maria, v.34, n.5, p.1401-1406, 2004.

5. CARVALHO, D. C.; BIASI, L. A.; TELLES, C. A. Organogênese do caquizeiro 'Fuyu' a partir de ápices meristemáticos. Revista Brasileira de Agrociência, Pelotas, v.10, n.3, p.303-307, 2004a.

6. CARVALHO, D. C.; BIASI, L. A.; RIBAS, L. L. F.; TELLES, C. A.; ZANETTE, F. Embriogênese somática do caquizeiro. Revista Brasileira de Fruticultura, Jaboticabal, v.26 n.2, p. 280-283, 2004b.

7. CARVALHO, R. I. N.; ZANETTE, F. Dinâmica da dormência de gemas de macieira 'Imperial Gala' durante o outono e inverno em região de baixa ocorrência de frio. Revista Brasileira de Fruticultura, Jaboticabal, v.26, n.1, p.65-68, 2004.

8. DUTRA, L. F.; KERSTEN, E.; FACHINELLO, J. C. Época de coleta, ácido indolbutírico e triptofano no enraizamento de estacas de pessegueiro. Scientia Agricola, Piracicaba, v.59, n.2, p.327-333, 2002.

9. FACHINELLO, J. C.; HOFFMANN, A.; NACHTIGAL, G. R. L.; KERSTEN, E.; FORTES, G. R. L. Propagação de plantas frutíferas de clima temperado. Pelotas: UFPEL, 1995. 178p.

10. GOMES, P. Fruticultura Brasileira. São Paulo: Ed. Nobel S.A., 1994. 153p.

11. GONTIJO, T. C. A.; RAMOS, J. D.; MENDONÇA, V.; PIO, R.; ARAUJO NETO, S. E.; CORRÊA, F. L. O. Enraizamento de diferentes tipos de estacas de aceroleira utilizando ácido indolbutírico. Revista Brasileira de Fruticultura, Jaboticabal, v.25, n.2, p.290-292, 2003.

12. HERTER, F. G.; MACHADO, L. B.; OLIVEIRA, M. F.; SILVA, J. B. Efeito do frio na brotação de gemas de pereira (Pyrus communis L.) cv. Carrick, em Pelotas, RS. Revista Brasileira de Fruticultura, Jaboticabal, v.23, n.2, p.261-264, 2001.

13. MINDÊLLO NETO, U. R. Enraizamento de estacas de pessegueiro em função do uso de ácido indolbutírico e fertilizante orgânico. Revista Brasileira de Fruticultura, Jaboticabal, v.27, n.1, p.92-94, 2005.

14. MINDÉLLO NETO, U. R.; TELLES, C. A.; BIASI, L. A. Enraizamento de estacas lenhosas de ameixeiras tratadas com ácido indolbutírico. Ciência Rural, Santa Maria, v.36, n.2, p.448-452, 2006.

15. MIZOBUTSI, G. P.; BRUCKNER, C. H.; SALOMÃO, L. C. C.; RIBEIRO, R. A.; MOTTA, W. F. Efeito da aplicação de cianamida hidrogenada e de óleo mineral em caquizeiro. Revista Brasileira de Fruticultura, Jaboticabal, v.25, n.1, p.89-92, 2003.

16. OLIVEIRA, A. P.; NIENOW, A. A.; CALVETE, E. O. Capacidade de enraizamento de estacas semi-lenhosas e lenhosas de cultivares de pessegueiro tratadas com AIB. Revista Brasileira de Fruticultura, Jaboticabal, v.25, n.2, p.282-285, 2003.

17. PAES, E. G. B.; ZUFFELLATO-RIBAS, K. C.; BIASI, L. A.; KOEHLER, H. S. Enraizamento de estacas de kiwizeiro (Actinidia deliciosa Lang et Ferguson cv. Bruno) nas quatro estações do ano. Scientia Agraria, Curitiba, v.4, n.1-2, p.69-76, 2003.

18. RICHARDSON, E. A.; SEELEY, S. D.; WALKER, D. R. A model for estimating the completion of rest for 'Redhaven' and 'Elberta' peach trees. Hortscience, Mount Vernon, v.9, n.4, p.331-332, 1974.

19. ROSSAL, P. A. L.; KERSTEN, E.; CONTER, P. F. Estudo comparativo da evolução do nível de triptofano em ramos de ameixeira (Prunus salicina Lindl.). Scientia Agricola, Piracicaba, v.54, n.3, p.174-177, 1997.

20. SIMEPAR. Instituto Tecnológico SIMEPAR - UFPR. Temperaturas mínimas horárias. Curitiba, setembro de 2005. Arquivo eletrônico $(403 \mathrm{~Kb})$ Word for Windows. 2005.

21. TOFANELLI, M. B. D.; ONO, E. R.; RODRIGUES, J. D. Potencial de enraizamento de estacas lenhosas de pessegueiro tratadas com ácido indolbutírico em diferentes concentrações e métodos de aplicação. Revista Brasileira de Agrociência, Pelotas, v.8, n.2, p.159-160, 2002a.

22. TOFANELLI, M. B. D.; CHALFUN, N. N. J.; HOFFMANN, A.; CHALFUN JUNIOR, A. Efeito do ácido indolbutírico no enraizamento de estacas de ramos semilenhosos de pessegueiro. Pesquisa Agropecuária Brasileira, Brasília, v.37, n.7, p.939-944, 2002b.

23. TOFANELLI, M. B. D.; ONO, E. R.; RODRIGUES, J. D. Método de aplicação de ácido indolbutírico no enraizamento de estacas herbáceas de pessegueiro. Revista Brasileira de Fruticultura, Jaboticabal, v.25, n.2, p.363-364, 2003a.

24. TOFANELLI, M. B. D.; RODRIGUES, J. D.; ONO, E. R. Método de aplicação do ácido indolbutírico na estaquia de cultivares de pessegueiro. Ciência e Agrotecnologia, Lavras, v.27, n.5, p.1031-1037, 2003b.

25. TOFANELLI, M. B. D.; RODRIGUES, J. D.; ONO, E. R. 2,6-Di-hidroxiacetofenona e tipo de corte basal no enraizamento de estacas semi-lenhosas de pessegueiro 'Okinawa', Ciência Rural, Santa Maria, v.35, n.2, p.462-464, 2005.

26. ZANETTE, F. Efeito de algumas temperaturas de estocagem sobre a quebra de dormência das gemas e a regeneração do sistema radical de porta-enxerto de macieira. Revista do Setor de Ciências Agrárias, Curitiba, v.4, p.43-47, 1982.

Recebido em 21/06/2006 Aceito em 22/08/2006 